\title{
EFFECT OF WELDING THERMAL CYCLE ON STRUCTURE-PHASE TRANSFORMATIONS AND PROPERTIES OF HAZ METAL OF ALLOYED 30Kh2N2MF
TYPE MEDIUM-CARBON STEEL
}

\author{
V.D. POZNYAKOV, V.A. KOSTIN, A.A. GAJVORONSKY, \\ I.A. MOSSOKOVSKAYA, V.V. ZHUKOV and A.V. KLAPATYUK \\ E.O. Paton Electric Welding Institute, NASU \\ 11 Bozhenko Str., 03680, Kiev, Ukraine. E-mail: office@paton.kiev.ua
}

\begin{abstract}
Thermostrengthened alloyed medium-carbon and carbon steels of average, increased and high hardness are widely used in manufacture of welded metal structures for car bodies. HAZ metal should also have corresponding values of yield strength considering the requirements necessary for providing of welded joint full-strength. However, mechanical properties of HAZ metal obtained by means of formation of specific complex of microstructures, generated in process of its cooling (welding modes), in contrast to steel, which acquires necessary complex of mechanical properties as a result of initial heat treatment (quenching and tempering). Preferred formation of martensite structures in HAZ metal of welded joints from given steels and saturation of this area by diffusible hydrogen result in increase of their susceptibility to cold crack formation. In this connection, this work represents the results of investigations aimed at study of effect of welding thermal cycles on nature of structural transformations, hardness, static strength and cold crack resistance of HAZ metal of high-strength alloyed medium-carbon steel of the 30Kh2N2MF type with 0.31 and $0.36 \%$ carbon content. Structure and kinetics of transformation of undercooled austenite was investigated using current methods of physical materials science by means of simulation of phase transformations on Gleeble 3800 machine. It is determined that austenite decomposition in the samples of $30 \mathrm{Kh} 2 \mathrm{~N} 2 \mathrm{MF}$ steel HAZ, independent on carbon content in it, takes place mainly in area of martensite transformation at cooling rate $w_{6} / 5=2.5-30{ }^{\circ} \mathrm{C} / \mathrm{s}$. It is shown that hardness and static strength of $\mathrm{HAZ}$ metal in steel with $0.36 \% \mathrm{C}$ are provided for the whole studied range of cooling rates. Similar properties of HAZ metal in steel with $0.31 \% \mathrm{C}$ can be achieved under condition of cooling at $600-500{ }^{\circ} \mathrm{C}$ and rate not less than $10{ }^{\circ} \mathrm{C} / \mathrm{s}$. The results of investigations can be used for optimizing welding modes of special equipment and further improvement of modes of steel heat treatment. 15 Ref., 4 Tables, 7 Figures.
\end{abstract}

Key words: high-strength alloyed steels, heat-affected zone, welding thermal cycles, CCT diagram of austenite decomposition, metal structure, metal hardness

At present time, thermostrengthened highstrength steels alloyed by chromium, nickel and molybdenum and containing $0.25-0.50 \%$ carbon are widely used in manufacture of welded assemblies and bodies of special designation wheeled equipment. Sometimes vanadium, aluminum and boron are used for microalloying of such steels. Steels, depending on designation, can have average $(H B \geq 2850 \mathrm{MPa})$, increased $(H B \geq$ $\geq 3350 \mathrm{MPa})$ and high $(H B \geq 3630 \mathrm{MPa})$ hardness. It is achieved after corresponding heat treatment consisting of quenching and tempering [1-4].

One of the main requirement made to such welded joints from given steels lies in the fact that hardness of HAZ metal should be not lower than that of base metal. It is obvious, considering the fact that structures from indicated steels are not quenched after welding and being subjected only to low-temperature tempering, that HAZ metal shall acquire necessary indices of hardness in as-welded condition.

It is known fact $[5,6]$ that mechanical properties of metal determine its structural composition. Besides, structure formation in HAZ metal of welded joints depends not only on steel chemical composition, but on welding thermal cycles as well. The metal can be soften under specific conditions if metal after heating is subjected to cooling with low rate. Its hardness and static strength rise, as a rule, with cooling rate increase.

Welded joints from high-strength alloyed medium-carbon steels are susceptible to cold crack formation. It is related with formation of hardening structures and residual tensile stresses in HAZ metal [7-10]. Presence of diffusible hydrogen in metal provokes for increase of possibility of cold crack formation and the process itself becomes more intensive [11, 12]. Heating of welded joints from medium-carbon high-strength steels is used 
SCIENTIFIC AND TECHNICAL

Table 1. Composition of samples of $30 \mathrm{Kh} 2 \mathrm{~N} 2 \mathrm{MF}$ type steel, \%

\begin{tabular}{|c|c|c|c|c|c|c|c|c|c|c|c|c|c|}
\hline $\begin{array}{c}\text { Sample } \\
\text { type }\end{array}$ & $\mathrm{C}$ & $\mathrm{Si}$ & $\mathrm{Mn}$ & $\mathrm{Cr}$ & $\mathrm{Ni}$ & $\mathrm{Mo}$ & $\mathrm{Cu}$ & $\mathrm{V}$ & $\mathrm{Al}$ & $\mathrm{Ti}$ & $\mathrm{S}$ & $\mathrm{P}$ \\
\hline $\mathrm{X}$ & 0.31 & 1.16 & 0.74 & 1.66 & 2.26 & 0.30 & 0.080 & 0.20 & 0.040 & 0.024 & 0.010 & 0.016 \\
\hline $\mathrm{H}$ & 0.36 & 1.32 & 0.81 & 1.65 & 2.34 & 0.50 & 0.062 & 0.20 & 0.037 & 0.025 & 0.010 & 0.019 \\
\hline
\end{tabular}

for reduction of risk of cold crack formation. On the one hand, this allows regulating the kinetics of phase transformations and forming the structures with increased cold crack formation resistance, and, on the other hand, developing the conditions for active hydrogen desorption from the welded joint metal.

In this connection, aim of the present work lies in study of effect of welding thermal cycles on nature of structural transformations, hardness, static strength and cold crack formation resistance of HAZ metal of alloyed medium-carbon high-strength steel of 30Kh2N2MF type with 0.31 and $0.36 \%$ carbon content.

Samples from medium-alloyed high-strength steel of $30 \mathrm{Kh} 2 \mathrm{~N} 2 \mathrm{MF}$ type with total content of alloying elements approximately $4 \%$ (Table 1 ) were taken as object for investigations.

Table 2 shows the mechanical properties of the samples in as heat-treated condition (quenching + low-temperature tempering).

Investigation procedures. Chemical analysis of the samples was carried out in accordance with GOST 18895-97 using optical emission spectrometer Spectrovak-1000 (Baird, USA).

Chemical etching in $4 \%$ alcoholic nitric acid solution was used for determination of samples' microstructure. The samples for investigations were manufactured by standard procedures applying diamond pastes of different particle size.

Structural analysis was carried out with the help of light microscope «Neophot-32» at 200 and 500 magnification. Digital images were recorded using «Olympus» digital camera. Microhardness of structural constituents and HAZ metal integral hardness was measured on LECO hardness meter M-400 at $100 \mathrm{~g}(H V 0.1)$ and $1 \mathrm{~kg}(H V 10)$ loading, respectively, on GOST 2999-59.

Nature of structural transformations in HAZ metal of samples from 30Kh2N2MF steel were studied by simulation of thermal deformation welding cycle (TDWC) on Gleeble 3800 machine, equipped with fast-response dilatometer [13]. The investigations were carried out apply- ing cylinder samples of $6 \mathrm{~mm}$ diameter and $80 \mathrm{~mm}$ length produced from rolled sheet of 12 and $20 \mathrm{~mm}$ thickness. In accordance with a procedure developed at the E.O. Paton Electric Welding Institute the samples were heated to $1250{ }^{\circ} \mathrm{C}$ in vacuum chamber and then cooled. At that, the parameters of welding thermal cycle (heat and time) were simulated with high accuracy in HAZ metal of joints in mechanized gas-shielded welding using $1.2 \mathrm{~mm}$ diameter solid wire and different modes of welding. Rate of sample heating from 20 to $1250{ }^{\circ} \mathrm{C}$ made $210{ }^{\circ} \mathrm{C} / \mathrm{s}$ (heating time $6 \mathrm{~s})$, and cooling rate in temperature range 600$500{ }^{\circ} \mathrm{C}$ was varied in $w_{6 / 5} 2.5-30{ }^{\circ} \mathrm{C} / \mathrm{s}$ range.

Procedure, represented in work [14], was used for determination of temperatures of transformation beginning and ending in investigation of kinetics of austenite decay.

Mechanical properties of HAZ metal (yield strength, ultimate tensile strength, elongation and reduction in area) were determined on the results of static tension test at $20{ }^{\circ} \mathrm{C}$ of standard samples (type II on GOST 6996-66). The samples were produced from $12 \times 12 \times 150 \mathrm{~mm}$ steel preliminary subjected to treatment on welding thermal cycle. In process of heat treatment the workpieces were heated by passing current to $1250{ }^{\circ} \mathrm{C}$ (heating rate $150{ }^{\circ} \mathrm{C} / \mathrm{s}$ ) and then cooled in such a way as to provide $2.5-30{ }^{\circ} \mathrm{C} / \mathrm{s}$ cooling rate, being regulated via change of intensity of workpiece argon purge, in $600-500{ }^{\circ} \mathrm{C}$ temperature interval.

Steel tendency to cold crack formation was studied on Implant method [15] using sample-inserts of $6 \mathrm{~mm}$ diameter without screw-shaped cut.

Critical stress $\sigma_{\mathrm{cr}}$, at which the sample does not failure during $24 \mathrm{~h}$, was taken as an index characterizing resistance of HAZ metal to cold crack formation.

Content of hydrogen in deposited metal was evaluated using «pencil probe» method. Mixture of distillated water with glycerin was applied as locking liquid.

Investigation results. Metal of sample $\mathrm{X}$ in as-delivered condition (without heat treatment)

Table 2. Mechanical properties of samples of 30Kh2N2MF type steel

\begin{tabular}{||c|c|c|c|c|c|c|c||}
\hline \hline Sample type & $\sigma_{0.2}, \mathrm{MPa}$ & $\sigma_{\mathrm{t}}, \mathrm{MPa}$ & $\delta_{5}, \%$ & $\psi, \%$ & $K C U_{+20}, \mathrm{~J} / \mathrm{cm}^{2}$ & $K C U_{-40}, \mathrm{~J} / \mathrm{cm}^{2}$ & $H B, \mathrm{MPa}$ \\
\hline $\begin{array}{c}\text { Requirements } \\
\text { of TA }\end{array}$ & $1470-1660$ & $1750-1960$ & $\geq 7$ & $\geq 15$ & $\geq 68.6$ & $\geq 29.4$ & $3880-4990$ \\
\hline $\mathrm{X}$ & $1426-1434$ & $1673-1680$ & $11.9-12.8$ & $54.1-57.5$ & $109-118$ & $100-108$ & $4150-4490$ \\
\hline $\mathrm{H}$ & $1470-1486$ & $1787-1802$ & $10.2-10.7$ & $46.6-49.2$ & $78-86$ & $74-85$ & $4400-4490$ \\
\hline
\end{tabular}



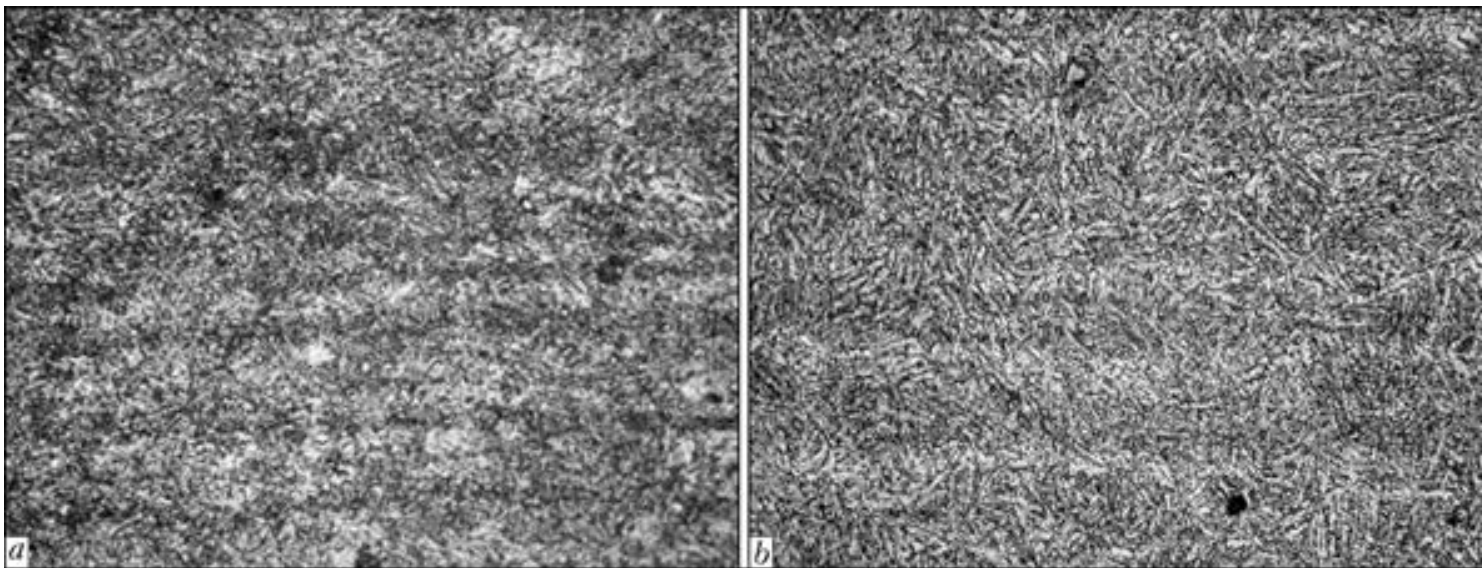

Figure 1. Structure $(\times 500)$ of $30 \mathrm{Kh} 2 \mathrm{~N} 2 \mathrm{MF}$ steel with $0.31(a)$ and $0.36(b) \% \mathrm{C}$ in as-delivered condition

has a structure consisting of mixture of upper and lower bainite with domination of upper bainite structure (Figure 1, $a$ ). Steel structure after heat treatment is transformed into martensite and lower bainite mixture (Figure 2, a). Light bands being observed in the structure of sample $\mathrm{X}$ are related with chemical micro-inhomogeneity (first of all, on carbon, sulfur and phosphor), forming in process of steel production. Used heat treatment provides some reduction of level of chemical inhomogeneity, but does not remove completely structure banding.

The investigations showed change of metal structure under TDWC effect. Figure 3, $a$ shows CCT diagram of undercooled austenite decomposition, which characterizes effect of $w_{6 / 5}$ cooling rate on phase-structure transformations in HAZ metal of welded joints of steel X samples. Temperature of beginning of austenite decomposition $A_{c 3}$ for given metal makes $870-880{ }^{\circ} \mathrm{C}$. Temperature of beginning of martensite (diffusion-free) transformation makes $350-355{ }^{\circ} \mathrm{C}$ and that of ending is $150-155^{\circ} \mathrm{C}$.

1.5 times increase of $H V 0.1$ hardness of martensite matrix from 3680 (at $2.5{ }^{\circ} \mathrm{C} / \mathrm{s}$ ) to $5070 \mathrm{MPa}\left(\right.$ at $30{ }^{\circ} \mathrm{C} / \mathrm{s}$ ) should be related with reduction of size of martensite packages ( $\mathrm{Fi}^{-}$ gure 4) due to increase of quantity of areas with crystallographic orientation favorable for development of martensite transformation. This is possibly an explanation of the fact that increase of cooling rate promotes for rise of static strength of HAZ metal, and its plastic properties redaction (Table 3). Figure 5 shows a change of microstructure of HAZ metal of steel $30 \mathrm{Kh} 2 \mathrm{~N} 2 \mathrm{MF}$ with $0.31 \%$ C. Microstructural investigations verified that transformations of undercooled austenite in HAZ metal take place only in martensite area at $w_{6} / 5=2.5-30{ }^{\circ} \mathrm{C} / \mathrm{s}$.

Martensite (M) is formed in area of HAZ metal overheating at $w_{6 / 5}=2.5{ }^{\circ} \mathrm{C} / \mathrm{s}$. Martensite package size makes approximately $h_{\mathrm{M}} \sim 34 \mu \mathrm{m}$ (Figures 4 and $5, a$ ) with $H V 0.1=3360-$ $3830 \mathrm{MPa}$ microhardness. Internal hardness ( $H V 10)$ of metal is approximately $3680 \mathrm{MPa}$, $\sigma_{0.2}=1060 \mathrm{MPa}, \delta_{5}=14.7 \%$

Increase of cooling rate from 2.5 to $20{ }^{\circ} \mathrm{C} / \mathrm{s}$ provides no significant changes of HAZ metal structure in overheating area. However, at that, size of martensite packages reduce from $32.8 \mu \mathrm{m}$ at $w_{6 / 5}=$ $=5{ }^{\circ} \mathrm{C} / \mathrm{s}$ to $19 \mu \mathrm{m}$ at $w_{6 / 5}=20{ }^{\circ} \mathrm{C} / \mathrm{s}$ (Figures 4 and 5 ). Integral hardness of metal during this rises from 4160 to $4670 \mathrm{MPa}$, and yield strength increases from 1127 to $1330 \mathrm{MPa}$. Its ductile properties at that decreases from 14.1 to $12.8 \%$.

Structure of metal in HAZ overheating area of $30 \mathrm{Kh} 2 \mathrm{~N} 2 \mathrm{MF}$ steel with $0.31 \% \mathrm{C}$ also consists
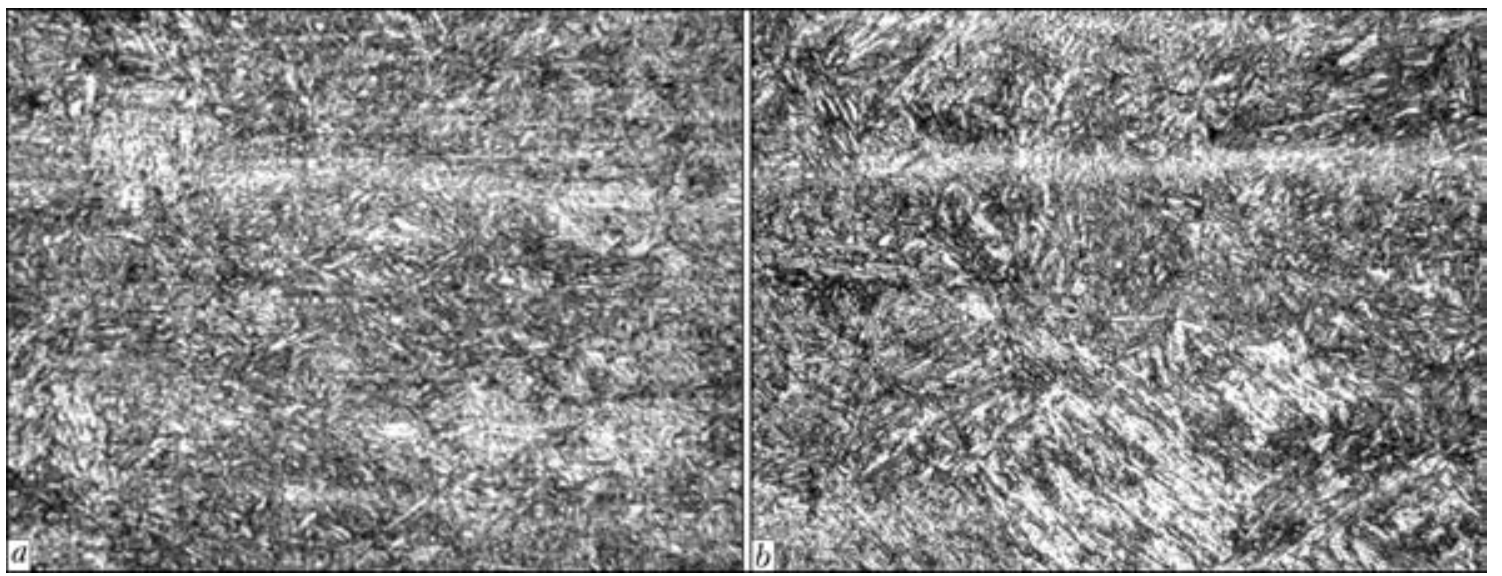

Figure 2. Structure $(\times 500)$ of $30 \mathrm{Kh} 2 \mathrm{~N} 2 \mathrm{MF}$ steel with $0.31(a)$ and $0.36(b) \% \mathrm{C}$ after quenching and low-temperature tempering 

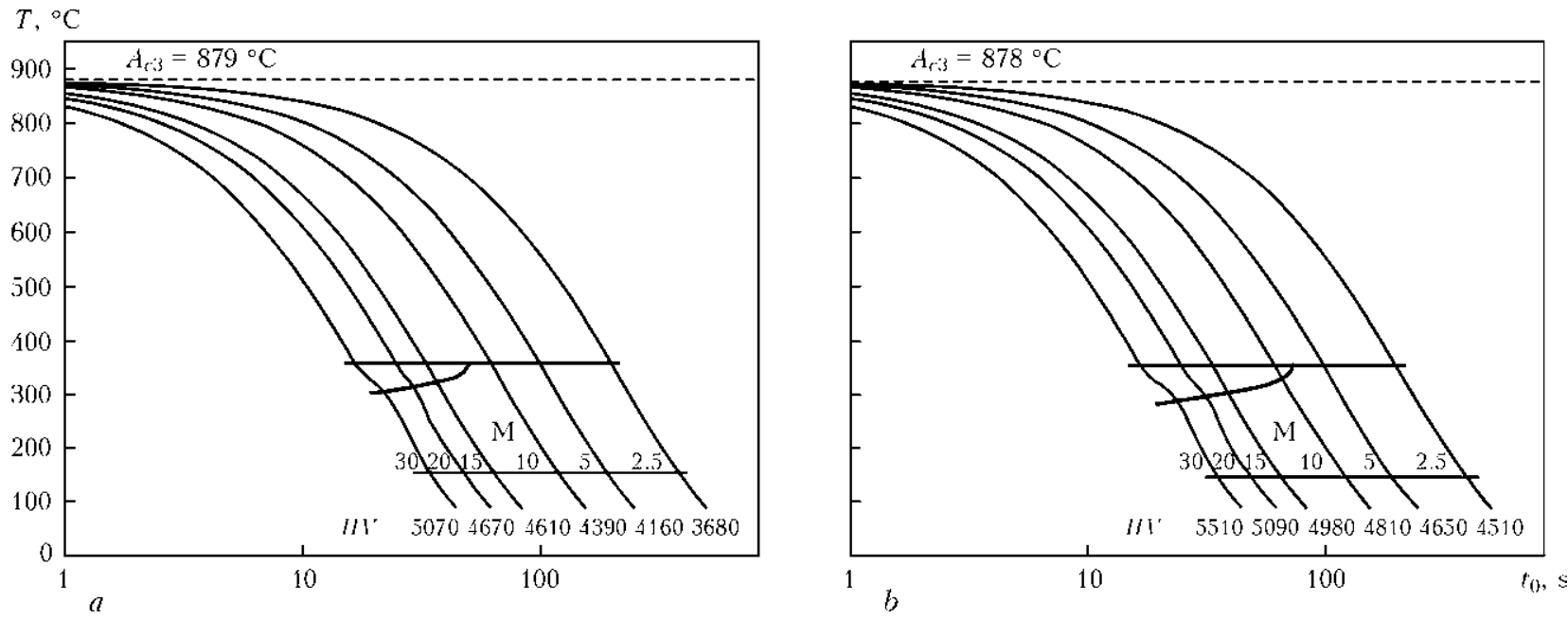

Figure 3. CCT diagrams of undercooled austenite decomposition in HAZ metal of joints from 30Kh2N2MF steel with $0.31(a)$ and $0.36(b) \% \mathrm{C}$ in arc welding: $t_{0}-$ cooling time

of martensite, size of packages of which does not exceed $12.5 \mu \mathrm{m}$ at $w_{6 / 5}=30{ }^{\circ} \mathrm{C} / \mathrm{s}$. At that, microhardness of martensite rises to $H V 0.1=$ $=4170-4720 \mathrm{MPa}$ and integral metal hardness increases to $5070 \mathrm{MPa}$ (Figures 4 and 5, $f$ ). Due to this fact $\sigma_{0.2}$ of HAZ metal increases to $1534 \mathrm{MPa}$, and $\delta_{5}$ and $\psi$ (ductility) decrease to 11.7 and $48.8 \%$, respectively.

Set dependencies of metal structure change in sample X showed formation of martensite structure of increased hardness in HAZ metal of given steel at $w_{6 / 5} \geq 20{ }^{\circ} \mathrm{C} / \mathrm{s}$. It is obvious that level of local internal stresses in metal structure at increase of cooling rate will also rise and its susceptibility to plastic deformation rapidly drop. In addition to rise of hydrogen content in HAZ metal, this develops the conditions at which indicated metal will have low cold crack resistance. It can be assumed based on mentioned above that cooling rate in HAZ metal should not exceed $20{ }^{\circ} \mathrm{C} / \mathrm{s}$ in welded joints from steel with carbon content $0.31 \%$ for prevention of cold crack formation.

Structure of metal of sample $\mathrm{H}$, containing $0.36 \% \mathrm{C}$, in-as delivered condition (without heat

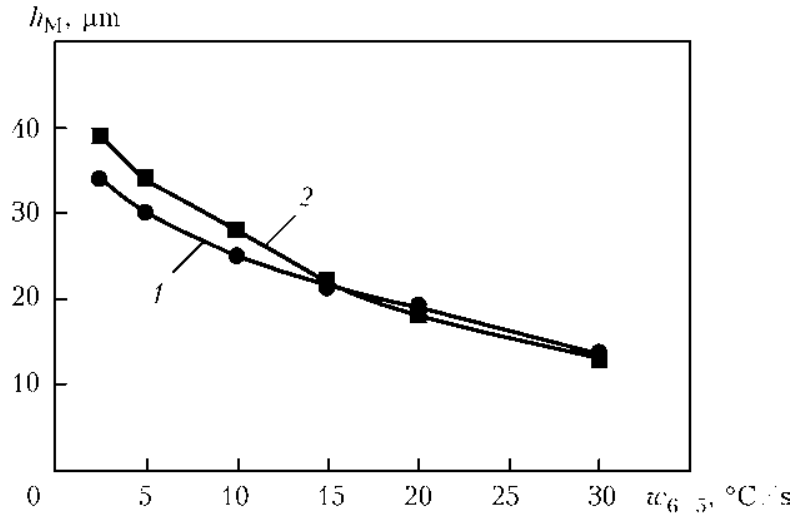

Figure 4. Effect of cooling rate on size of martensite packages $h_{\mathrm{M}}$ in structure of HAZ metal of $30 \mathrm{Kh} 2 \mathrm{~N} 2 \mathrm{MF}$ steel with 0.31 (1) and $0.36(2) \% \mathrm{C}$ treatment) also consists of mixture of upper and lower bainite (see Figure 1, b). Heat treatment (quenching + low-temperature tempering) transforms the steel structure in the mixture of martensite, upper and lower bainite (see Figure 2, b).

Structure of HAZ metal under TDWC effect is changed, size of structural constituents and metal hardness rise. Generalized results of investigations of effect of cooling rate on structurephase transformations in HAZ metal are represented in Figure 3, $b$ in form of CCT diagram of undercooled austenite decomposition. Figure 4 shows change of size of structural constituents, and Figure 5 represents typical microstructures, formed in area of overheating of HAZ metal under effect of TDWC. Data on change of mechanical properties of HAZ metal of 30Kh2N2MF type steel with $0.36 \% \mathrm{C}$ under effect of TDWC are given in Table 4.

Carried examinations showed that transformations of undercooled austenite in HAZ metal of steel with $0.36 \% \mathrm{C}$ in $2.5-30{ }^{\circ} \mathrm{C} / \mathrm{s}$ cooling rate range take place exclusively in martensite area, the same as in steel with $0.31 \% \mathrm{C}$. However, formation of martensite in it starts at lower $\left(340-350{ }^{\circ} \mathrm{C}\right)$ transformation temperature and finishes at $140{ }^{\circ} \mathrm{C}$ (see Figure $3, b$ ) in contrast to steel with $0.31 \%$ C. Similar to previous case

Table 3. Mechanical properties of HAZ metal of samples of $30 \mathrm{Kh} 2 \mathrm{~N} 2 \mathrm{MF}$ type steel with $0.31 \% \mathrm{C}$

\begin{tabular}{||c|c|c|c|c|c||}
\hline $\begin{array}{c}w_{6 / 5}, \\
{ }^{\circ} \mathrm{C} / \mathrm{s}\end{array}$ & $\sigma_{0.2}, \mathrm{MPa}$ & $\sigma_{\mathrm{t}}, \mathrm{MPa}$ & $\delta_{5}, \%$ & $\psi, \%$ & $\begin{array}{c}H V 10, \\
\mathrm{MPa}\end{array}$ \\
\hline 2.5 & 1060 & 1250 & 14.7 & 58.6 & 3680 \\
\hline 5 & 1127 & 1330 & 14.1 & 58.0 & 4160 \\
\hline 10 & 1200 & 1410 & 13.0 & 57.0 & 4390 \\
\hline 15 & 1300 & 1510 & 12.4 & 55.1 & 4610 \\
\hline 20 & 1330 & 1540 & 12.8 & 54.8 & 4670 \\
\hline 30 & 1534 & 1684 & 11.7 & 48.8 & 5070 \\
\hline
\end{tabular}



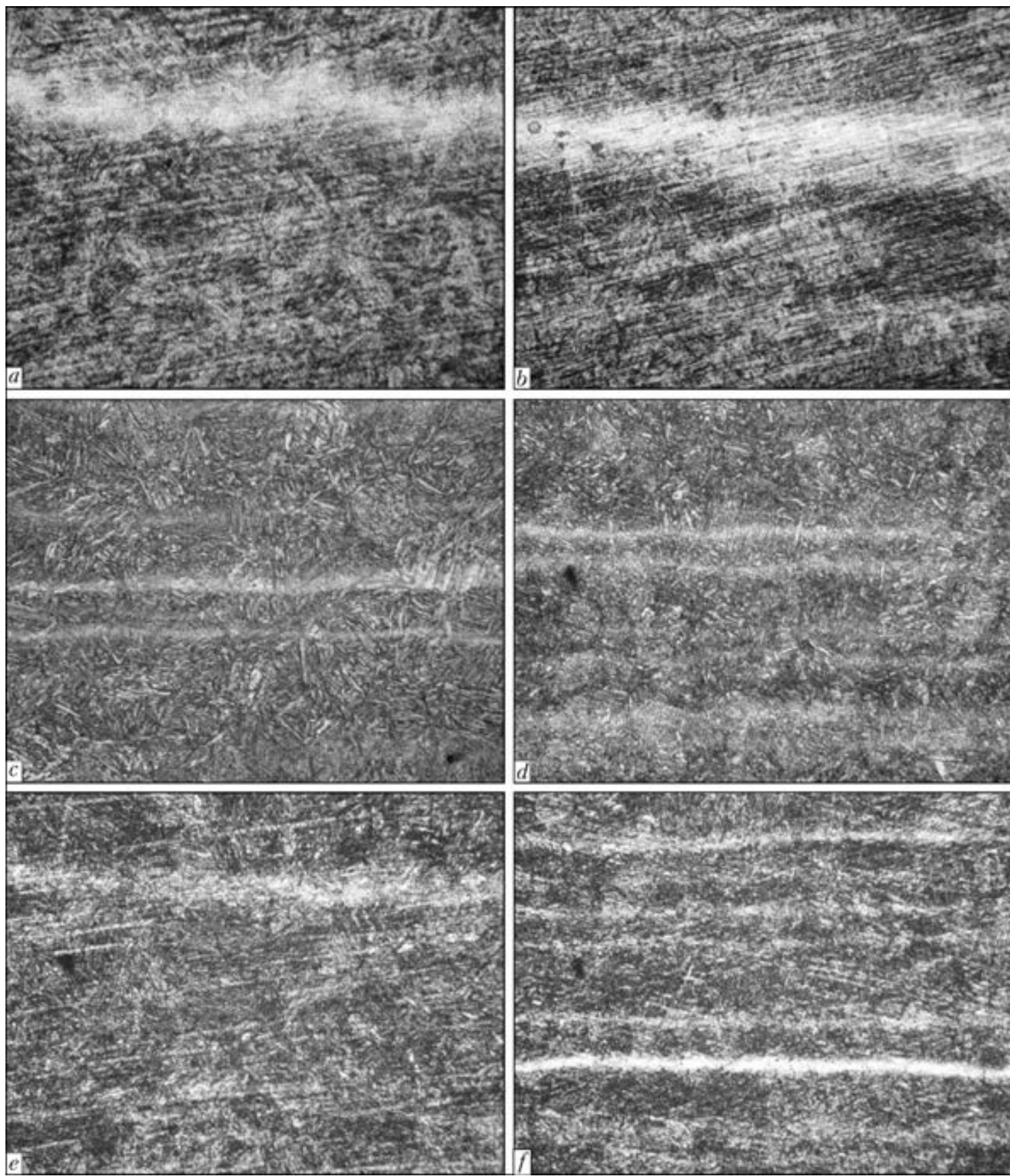

Figure 5. Microstructure $(\times 500)$ of HAZ metal in overheating area of $30 \mathrm{Kh} 2 \mathrm{~N} 2 \mathrm{MF}$ steel, containing $0.31 \% \mathrm{C}$, at $w 6 / 5=$ $=2.5(a), 5(b), 10(c), 15(d), 20(e)$ and $30(f){ }^{\circ} \mathrm{C} / \mathrm{s}$

the cooling rate has noticeable effect on parameters of HAZ metal structure. Data on change of size of martensite packages, microstructure and integral hardness of HAZ metal in area of this steel overheating are presented in Figures $4, b$ and $3, b$, respectively.

The results of metallograpy indicate that martensite (Figure $6, a$ ), having approximately $h_{\mathrm{M}} \sim 37.1 \mu \mathrm{m}$ (see Figure 4) size packages and $H V 0.1=3930-4730 \mathrm{MPa}$ microhardness, is formed in structure of HAZ metal of steel with $0.36 \% \mathrm{C}$ at $w_{6}=2.5{ }^{\circ} \mathrm{C} / \mathrm{s}$. Integral hardness of quenched HAZ metal under specified cooling conditions makes $H V 10==4510 \mathrm{MPa}, \sigma_{0.2}=$ $=1240 \mathrm{MPa}, \delta_{5}=12.8 \%$.
Increase of cooling rate from 5 to $15{ }^{\circ} \mathrm{C} / \mathrm{s}$ promotes for reduction of martensite packages from 33.8-22.5 $\mu \mathrm{m}$ and rise of its microhardness from $3810-4850$ to $4470-5000 \mathrm{MPa}$ (see Figure 6). At that, integral hardness of quenched HAZ metal increases from 4550 to $4980 \mathrm{MPa}$, $\sigma_{0.2}$ changes from 1262 to $1445 \mathrm{MP}$, and elongation indices drop from 12.7 to $11.2 \%$.

The most observable change of structure parameters in area of overheating of HAZ metal of steel with $0.36 \% \mathrm{C}$ was noticed in the samples being cooled at $w_{6 / 5}=30{ }^{\circ} \mathrm{C} / \mathrm{s}$. At that, martensite structure with $H V 0.1=4460-5200 \mathrm{MPa}$ microhardness and $h_{\mathrm{M}} \sim 12.5 \mu \mathrm{m}$ size packages is formed in HAZ metal. Under such conditions of 
SCIENTIFIC AND TECHNICAL

Table 4. Mechanical properties of HAZ metal of samples from $30 \mathrm{Kh} 2 \mathrm{~N} 2 \mathrm{MF}$ steel with $0.36 \% \mathrm{C}$

\begin{tabular}{||c|c|c|c|c|c||}
\hline $\begin{array}{c}\tau_{6 / 5}, \\
{ }^{\circ} \mathrm{C} / \mathrm{s}\end{array}$ & $\sigma_{0.2}, \mathrm{MPa}$ & $\sigma_{\mathrm{t}}, \mathrm{MPa}$ & $\delta_{5}, \%$ & $\psi, \%$ & $\begin{array}{c}H V 10, \\
\mathrm{MPa}\end{array}$ \\
\hline 2.5 & 1240 & 1460 & 12.8 & 55.8 & 4510 \\
\hline 5 & 1262 & 1490 & 12.7 & 55.0 & 4550 \\
\hline 10 & 1395 & 1615 & 12.1 & 53.6 & 4810 \\
\hline 15 & 1445 & 1705 & 11.2 & 48.3 & 4980 \\
\hline 30 & 1607 & 1896 & 10.4 & 46.8 & 5510 \\
\hline
\end{tabular}

structure formation quenched HAZ metal acquires integral hardness at the level of $H V 10=$ $=5510 \mathrm{MPa}$. At that, yield strength of metal increases to $1607 \mathrm{MPa}$, elongation and reduction in area reduce to 10.4 and $46.8 \%$, respectively.

Thus, it can be noted that martensite structure with increased hardness is formed in HAZ metal of steel with $0.36 \% \mathrm{C}$ at lower cooling rates $\left(\geq 15{ }^{\circ} \mathrm{C} / \mathrm{s}\right)$, in contrast to steel with $0.31 \% \mathrm{C}$. It can be assumed, based on mention above, that prevention of cold crack formation in welded joints requires such technological parameters of welding modes for joints from 30Kh2N2MF steel with $0.36 \% \mathrm{C}$, at which cooling rate of $\mathrm{HAZ}$ metal will not exceed $15{ }^{\circ} \mathrm{C} / \mathrm{s}$.

Quantitative estimation of susceptibility of $30 \mathrm{Kh} 2 \mathrm{~N} 2 \mathrm{MF}$ type steel to cold crack formation
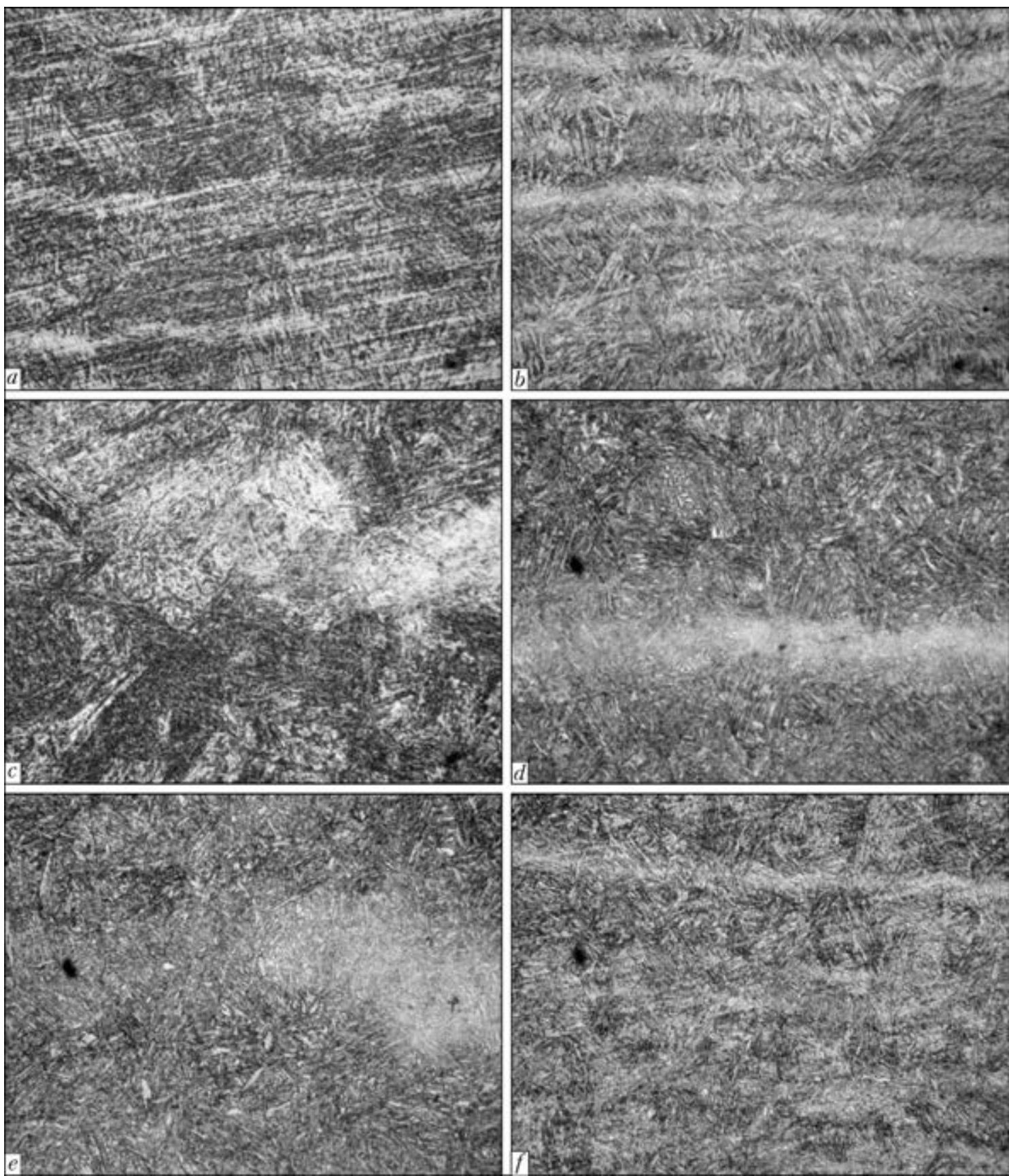

Figure 6. Microstructure $(\times 500)$ of HAZ metal in overheating area of $30 \mathrm{Kh} 2 \mathrm{~N} 2 \mathrm{MF}$ steel, containing $0.36 \% \mathrm{C}$, at $\omega_{6} / 5=$ $=2.5(a), 5(b), 10(c), 15(d), 20(e)$ and $30(f){ }^{\circ} \mathrm{C} / \mathrm{s}$ 
was carried out using samples-inserts produced from steel with $0.36 \% \mathrm{C}$.

Deposition, joining sample-insert with support plate, was performed by mechanized welding in $\mathrm{Ar}$ $+20 \% \mathrm{CO}_{2}$ gas mixture using solid Sv-08GSMT grade wire of $1.2 \mathrm{~mm}$ diameter. Content of diffusible hydrogen in metal deposited by indicated wire in as-delivered condition makes $[\mathrm{H}]_{\text {dif }}=$ $=4.2 \mathrm{~cm}^{3} / 100 \mathrm{~g}$. Special treatment of wire before welding, which lied in its heating in furnace to $240{ }^{\circ} \mathrm{C}$, holding at this temperature during $2 \mathrm{~h}$, cooling in furnace to ambient temperature and further mechanical grinding, allowed reducing $[\mathrm{H}]_{\mathrm{dif}}$ content in the deposited metal to $1.1 \mathrm{~cm}^{3} / 100 \mathrm{~g}$. Figure 7 shows the results of tests on Implant method. They give characteristic of $\sigma_{\mathrm{cr}}$ change in HAZ metal of $30 \mathrm{Kh} 2 \mathrm{~N} 2 \mathrm{MF}$ steel depending on temperature of sample pre-heating and content of diffusible hydrogen in the deposited metal.

Carried investigations indicated that increase of $[\mathrm{H}]_{\text {dif }}$ in the deposited metal from 1.1 to $4.2 \mathrm{~cm}^{3} / 100 \mathrm{~g}$ provides for virtually 2 times reduction of resistance of HAZ metal to cold crack formation. Preheating to $150-200{ }^{\circ} \mathrm{C}$ allows for significant increase of resistance of welded joints produced by Sv-08GSMT wire to given type of fracture.

\section{Conclusions}

1. It is determined that transformations of undercooled austenite in HAZ metal of alloyed medium-carbon steel 30Kh2N2MF independent on content of carbon in it, take place in area of martensite transformation with formation of insignificant quantity of upper and lower bainite at $w_{6 / 5}=2.5-30{ }^{\circ} \mathrm{C} / \mathrm{s}$.

2. Increase of sample cooling rate from 2.5 to $30{ }^{\circ} \mathrm{C} / \mathrm{s}$ and content of carbon from 0.31 to $0.36 \%$ provides for rise of HAZ metal hardness in overheating area from 3680 to 5070 and from 4390 to $5420 \mathrm{MPa}$, respectively. At that, its static strength also increases, whereas ductility reduces.

3. Prevention of cold crack formation in welded joints requires such technological parameters of welding modes for $30 \mathrm{Kh} 2 \mathrm{~N} 2 \mathrm{MF}$ steel with $0.31-0.36 \% \mathrm{C}$, at which HAZ metal cooling rates will not exceed $15{ }^{\circ} \mathrm{C} / \mathrm{s}$ and diffusible hydrogen content in the deposited metal makes $1.5 \mathrm{~cm}^{3} / 100 \mathrm{~g}$.

4. Increase of $[\mathrm{H}]_{\mathrm{dif}}$ content in deposited metal from 1.1 to $4.2 \mathrm{~cm}^{3} / 100 \mathrm{~g}$ provides for 2 times reduction of cold crack formation resistance of HAZ metal of 30Kh2N2MF type steel. Preheating to $150-200{ }^{\circ} \mathrm{C}$ can increase cold crack formation resistance of welded joints produced by $\mathrm{Sv}$ 08GSMT wire.
$\sigma_{\mathrm{Cr}}, \mathrm{MPa}$

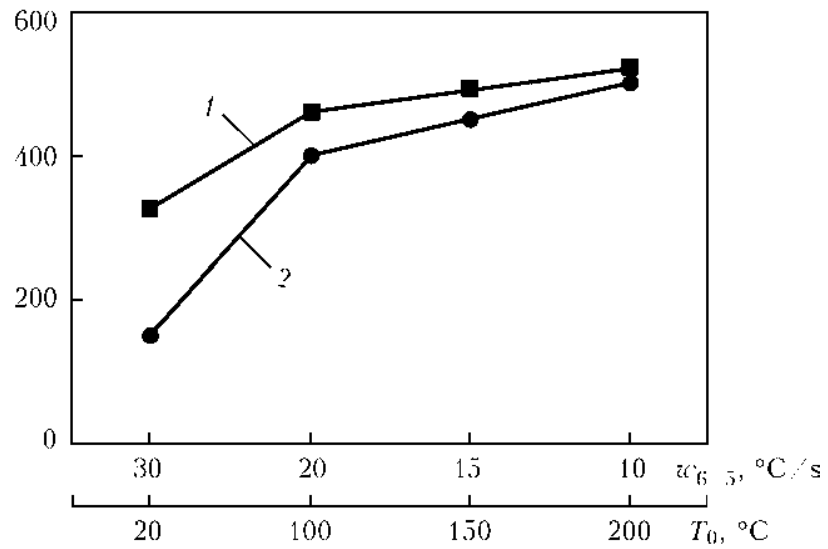

Figure 7. Effect of sample preheating temperature $T_{0}$ and content of diffusible hydrogen in deposited metal on susceptibility to cold crack formation of HAZ metal of 30Kh2N2MF type steel: $1-[\mathrm{H}]_{\text {dif }}=1.1 ; 2-4.2 \mathrm{~cm}^{3} / 100 \mathrm{~g}$

1. Tolten, G.T. (2006) Steel heat treatment: Metallurgy and technologies. Front cover. CRC Press (Technology \& Engineering).

2. Kashirsky, Yu.V., Koloskov, M.M. (2000) Information bank on machine building materials and processing modes. Tyazh. Mashinostroenie, 4, 12-19.

3. Goldshtejn, M.I., Grachev, S.V., Veksler, Yu.G. (1985) Special steels: Manual for higher education institutions. Moscow: Metallurgiya.

4. Bolshakov, V.I., Dolzhenkov, I.E., Dolzhenkov, V.I. (2002) Technology of heat and combined treatment of metal products: Manual for higher education institutions. Dnepropetrovsk: Gaudeamus.

5. Kuchuk-Yatsenko, S.I., Grigorenko, G.M., Novikova, D.P. et al. (2007) Effect of energy input on ductile properties of flash butt welded joints in steel X70. The Paton Welding J., 6, 2-6.

6. Medovar, L.B., Saenko, V.Ya., Polishko, A.A. et al. (2010) Effect of ESC LM thermal cycle on structure of model multilayer ingot. Zbirnyk Nauk. Prats $M U S B, 1,75-83$.

7. Seo, J.S., Kim, H.J., Ryoo, H.S. (2008) Microstructure parameter controlling weld metal cold cracking. J. Achievements in Materials and Manufact. Eng., 27(Issue 2), 199-202.

8. Sterenbogen, Yu.A. (1986) Some factors determining the resistance of HAZ metal of martensitic steels to cold cracking. Avtomatich. Svarka, 6, 5-8.

9. Skulsky, V.Yu. (2009) Peculiarities of kinetics of delayed fracture of welded joints of hardening steels. The Paton Welding J., 7, 12-17.

10. Gajvoronsky, A.A., Sarzhevsky, V.A., Gordonny, V.G. (1997) Weldability of medium-carbon alloyed steel 38Kh2MYuA. Avtomatich. Svarka, 4, 20-24, 33.

11. Li, S., Akiyama, E., Yuuji, K. et al. (2010) Hydrogen embrittlement property of a $1700 \mathrm{MPa}$ class ultrahigh strength tempered martensitic steel. Sci. and Technol. Adv. Materials, 11, 1-6.

12. Wongpanya, P., Boellinghaus, Th., Lothongkum, G. (2008) Heat treatment procedures for hydrogen assisted cold cracking avoidance in S 1100 OL steel root welds. Welding in the World, 52, 671-678.

13. Grigorenko, G.M., Kostin, V.A., Orlovsky, V.Yu. (2008) Current capabilities of simulation of austenite transformations in low-alloyed steel welds. The $\mathrm{Pa}$ ton Welding J., 3, 22-24.

14. Cherepin, V.T. (1968) Experimental technique in physical metals science. Kiev: Tekhnika.

15. Makarov, E.L. (1981) Cold cracks in welding of alloyed steels. Moscow: Mashinostroenie. 